\title{
Correspondence
}

\section{Reality of the concept of organic psychiatry DeAR SIRS}

I would suggest that it is now time for the segregation of mental handicap, and the stigma that goes with it, to be removed once and for all from our highly scientific, advanced and progressive society. As the sub-specialty of mental handicap (now mental infirmity) is concerned with the organic state of the brain, it could be renamed 'organic psychiatry'. In this way greater justice will be done to the 'Cinderella' of psychiatric practice, opening up a vast area for research and the understanding of human intellectual development and behaviour.

In the meantime the confusion continues unabated. The DHSS uses the term 'Mental Handicap'. The Royal College of Psychiatrists justifiably, though belatedly, terms it the 'psychiatry of mental handicap' which I suspect is not fully accepted by the DHSS. In medico-legal matters, the term 'mental infirmity' is applied. It seems to be that there is no communication or agreement between the custodians of the service for mentally handicapped people. This could easily be obtained if the psychiatric service of mental handicap is regarded as a sub-specialty of 'organic psychiatry' and the social care of mentally handicapped and normal people is entrusted to a 'Care Service' based in each District and separate from any psychiatric service.

Such measures would: remove prejudice against mentally handicapped people; bring uniformity to the concept; enhance the research and understanding of organically based psychiatry and up-grade the treatment and care given in each hospital; give mentally handicapped people the opportunity to remain in society being cared for by specially trained staff; remove the present confusion regarding the terminology of mental handicap; and allow the Government to save money, as a hospital-based service (which is unnecessary) is more costly than a District-based 'Care Service'.

Refusal to change and the continuation of unscientific practice will be regarded as unforgivable by future generations. A change in the terminology would bring the sub-specialty within the auspices of psychiatry and the resultant interest and enthusiasm would bring new hope to the practice of psychiatry, thereby breaking down the barrier that now excludes mentally infirm people.

Brockhall Hospital

U. J. DEY

Old Langho, Blackburn

\section{Mental Health Review Tribunals \\ Dear Sirs}

For Dr Anne Farmer (Bulletin, February 1984, 8, 23-24) to suggest that a psychiatrist might opt for Section 3 of the new Act rather than Section 2 in order to allow time to prepare a proper Tribunal report is treading on very dangerous ground indeed.

She describes an old lady in a general hospital who is deeply deluded. She is a recluse, and some three years before had been admitted to a general hospital under the provisions of the National Assistance Act suffering from malnutrition and hypothermia. Now she refuses admission to a psychiatric hospital and one may presume she is totally without insight. She was, therefore, admitted under Section 2 of the Act and subsequently discharged by a Tribunal within the 28-day period on the grounds that she was no longer a danger to herself. The Tribunal expressed the hope that she would remain informally.

I am puzzled to know why a Section 2 was considered at all. The diagnosis was in no doubt. She was a very sick woman who was obviously going to need more than 28 days compulsory treatment for her psychiatric illness. She fulfilled the criteria of Section 3 in that she suffered from mental illness of a nature or degree which made it appropriate for her to receive medical treatment in a hospital, and it was necessary for her to receive such treatment in the interests of her health.

Glenside Hospital

R. W. K. REEVES

Stapleton, Bristol

\section{Services for people with mental handicap}

\section{DeAr SiRs}

The letter by Mr Russell on 'Mental handicap servicesthe future' (Bulletin, December 1983, 7, 224) prompts me to put my thoughts on paper regarding, firstly, the role of consultant psychiatrists in mental handicap. These are: (i) The prevention of abnormal psychological stress to the person with handicap by the modification of abnormal and stressful lifestyles. (ii) The diagnosis and treatment of psychiatric illness. (iii) The support of caring groups, including families in whom there is collective psychopathology. (iv) Participation in drawing out personalized programmes of care on a multidisciplinary team basis. The team should consist of the patient and his family and those care workers best able to help with his problem.

Secondly, the chief roles that the hospital plays in the mental handicap service at the present time are: (i) To provide intensive supervision and treatment for people with handicap who are mentally ill. (ii) To provide children and adults with periods of short-term care for medical, nursing, clinical, psychological, dental and social reasons. (iii) To provide homes for a substantial number of people who have been in hospital all their adult lives. 
As more community based teams are developed, then the demands made on the hospital will change. This will enable the psychiatrist to cast off his custodial role, with the inappropriate task of maintaining abnormally medically orientated lifestyles, and taking responsibility for people with mental handicap who are mentally healthy.

This leads to my third point regarding the use of punishment in hospitals, schools and care establishments for people with mental handicap. To my mind, to knowingly cause suffering to a child or adult in any situation is unacceptable. Our task is to create a supportive and stimulating environment aimed at the relief of suffering and providing compensations for physical, mental, educational and social deficits. Qualities such as kindness, consideration, sympathy, understanding and forgiveness should be to the fore.

However, if punishment is used, a standing ethical committee with power of veto should be set up to review any behavioural programme which contains any aversive or depriving element, such as solitary confinement, electric shock, deprivation of food and water. For the ethical committee to have any credibility as an impartial body, a Justice of the Peace, a clergyman, a member of a voluntary organization such as MENCAP and an educationalist should be among the committee members. Only specified staff should administer such a programme, and it must be fully documented so that if it does not work, it can promptly be stopped. It should only be considered if conventional methods have failed, and should be combined in any case with a programme aimed at positively reinforcing desirable skills and behaviours.

Bryn-y-Neuadd Hospital

Llanfairfechan, Gwynedd

J. Aled Williams

\section{Psychiatry at the Careers Fair \\ Dear Sirs}

Further to the account (Bulletin, December 1983, 7, 222) by Professor Goldberg of the participation of the University of Manchester Department of Psychiatry in a Careers Fair last year, I thought it might be of interest to some readers to report that a colleague of mine, Dr John Hurst, and I have for the last two years been offered a stand for Mental Handicap at the Careers Fair at the Queen Elizabeth Postgraduate Medical Centre, Birmingham. Both fairs have been held in November and have been organized by the BMA. Last year arrangements were made to spread the attendance more evenly throughout the day, and included an additional evening session mainly for postgraduates.

I wish we had had the benefit of the video-tape which had been prepared by Professor Bicknell, but we had some visual aids which we hope were eye-catching. We also had handout copies of an article written by Sally Burningham originally published in BMA News Review, August 1982, and which was one of their 'Student Scene' series.
Organizing and manning a stall at a Careers Fair, even on modest lines, requires a good deal of thought and time. From the quantity of enquiries one wonders whether it is a balanced equation, but the quality of the enquiries settled our minds that it was, indeed, well worthwhile. We did not expect a flood of interest in our specialty, but we were encouraged by what we received, and are sure there is a need to make information freely available to those contemplating their future career, particularly in psychiatry or paediatrics.

MICHAEL YORK-MOORE

Lea Castle Hospital

Wolverley, Kidderminster, Worcs.

\section{Split consultant posts-psychiatry of mental handicap/any other branch of psychiatry}

DEAR SIRS

I would like to enlist the help of readers of the Bulletin to identify changing trends in appointing psychiatrists to joint appointments in two different branches of psychiatry. My interest is in whether or not such joint appointments are satisfactory, and how the current holders view their posts. New job descriptions still in the planning stage would also be of interest to me.

To assist readers my questions are these: (i) How many such posts do you know of? Please name the present holder, or, if vacant, when the post was last advertised. (ii) How many sessions are spent in mental handicap, and how many in the other branch of psychiatry? (Please specify the branch.) (iii) Please comment on the success or otherwise of these posts, outlining areas of difficulty and advantage as briefly as possible.

St George's Hospital Medical School

SHeila Hollins

London SW17

Facing up to new challenges

\section{DeAR SiRs}

Dr Flowerdew (Bulletin, January 1984, 8, 26-27) has expressed the gut feelings of psychiatrists practising today under the new Mental Health Act. What he applied to detained patients can equally be applied to informal patients, who are often detained within the doctor-patient relationship. Our defences-ECTs, leucotomy, neuroleptics, even psychotherapy-are crumbling. We are left with our naked anxiety and a new type of psychotherapy, i.e. coming down to earth and coming to terms with the patient, even the psychotic patient, and a multidisciplinary approach involving social manipulation.

Will psychiatrists rise up to this new and uncomfortable challenge? Should not the Membership Examination and the visits by the Accreditation Teams reflect this challenge and help the future psychiatrist to face it, even at the expense of academic achievements?

Prestwich Hospital

Victor S. Nehama

Prestwich, Manchester 